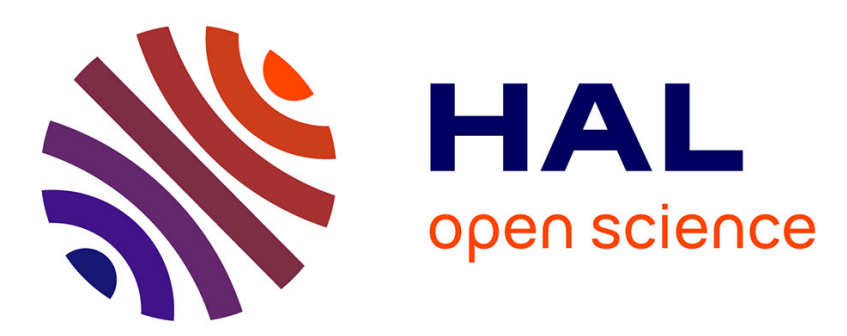

\title{
Leakage Inductance Analytical Calculation for Planar Components With Leakage Layers
}

\author{
Wenhua Tan, Xavier Margueron, Laurent Taylor, Nadir Idir
}

\section{To cite this version:}

Wenhua Tan, Xavier Margueron, Laurent Taylor, Nadir Idir. Leakage Inductance Analytical Calculation for Planar Components With Leakage Layers. IEEE Transactions on Power Electronics, 2016, 31 (6), pp.4462 - 4473. 10.1109/TPEL.2015.2471090 . hal-01886543

\section{HAL Id: hal-01886543 \\ https://hal.science/hal-01886543}

Submitted on 2 Oct 2018

HAL is a multi-disciplinary open access archive for the deposit and dissemination of scientific research documents, whether they are published or not. The documents may come from teaching and research institutions in France or abroad, or from public or private research centers.
L'archive ouverte pluridisciplinaire HAL, est destinée au dépôt et à la diffusion de documents scientifiques de niveau recherche, publiés ou non, émanant des établissements d'enseignement et de recherche français ou étrangers, des laboratoires publics ou privés. 


\title{
Leakage Inductance Analytical Calculation for Planar Components with Leakage Layers
}

\author{
Wenhua Tan, Xavier Margueron, Member, IEEE, Laurent Taylor, Nadir Idir, Member, IEEE
}

\begin{abstract}
Planar magnetic components are promising solutions for the integration of power electronic systems. The leakage inductance of such components plays an essential role in power converters. In this paper, an analytical modeling method for leakage inductance computation is developped for planar components with plasto-ferrite leakage layers. This method is based on the solution of Poisson's equations for magneto-static using multilayered Green's functions. The obtained formulations are general and precise and have been validated by numerical tests. Experimental characterizations have been performed on two magnetic components: A planar LLC and planar common mode choke. The obtained results show that with the described method, the static leakage inductance of planar components can be accurately estimated.
\end{abstract}

Index Terms-Leakage inductance, planar component, magnetic shunt, Green's function.

\section{INTRODUCTION}

$\mathbf{T}$ HE trends toward integration of power electronic systems make planar magnetic components prevalent solutions to realize more compact power converters [1], [2]. These components exhibit low profile, high power density and high reproducibility compared to other types of magnetic components. The leakage inductance of such component is a topic of huge interest. Indeed, due to their low profile, their leakage inductance value is usually supposed to be low [3]. For many applications, this low value can be an advantage because transformer's leakage inductance may cause extra losses, stress on components and ElectroMagnetic Interference (EMI) problems due to high frequency voltage oscillations [4][6].

On the opposite, two main applications can find the usefulness of a high leakage inductance. For resonant converter LLC (Fig. 1(a)), the leakage inductance $L_{l k}$ can be used for Zero Voltage Switching (ZVS), without adding an extra inductor [7], even if this leakage inductance can also causes voltage imbalance [8] or high voltage oscillations [9]. This leakage inductance must have then a specific value for typical softswitching converters [10] or Dual Active Bridge (DAB) for example [11]. If its value is not sufficient, some supplementary resonant inductor has to be added [12], [13].

Manuscript received March 13, 2015; revised June 25, 2015; accepted August 8, 2015

W. Tan, X. Margueron and L. Taylor are with Laboratory of Electrical Engineering and Power Electronics, Ecole Centrale de Lille, CS20048, 59650, Villeneuve d'Ascq, France e-mail: wenhua.tan@yahoo.cn; xavier.margueron@eclille.fr; laurent.taylor@ec-lille.fr.

N. Idir is with Laboratory of Electrical Engineering and Power Electronics, University of Lille 1, 59655, Villeneuve d'Ascq, France e-mail: Nadir.Idir@univ-lille1.fr.
For EMI filters, the leakage inductance of a common-mode (CM) choke can also be used for filtering differential mode (DM) perturbations [14]-[18]. For example, in [14], a leakage layer has been integrated between Printed Circuit Board (PCB) inside a pot core while in [15], the leakage layer has been inserted inside a mixed toroidal/EQ planar core. In both case, this leakage layer enable to increase the leakage inductance of the CM inductor. Other integrated EMI filters using CM leakage inductance to filter DM perturbations have also been reported in the past years, including flexible multilayers [16], combined toroidal cores for DM and CM chokes [17] or using magnetic epoxy mixture [18].

As discussed earlier, regarding planar components (transformers or CM chokes), their leakage inductances can be then increased by adding some supplementary leakage layers (also called magnetic shunt) such as Ferrite Polymer Composite (FPC) between the component's windings [6], [15], [19], [20]. Resonant converters or CM inductors require a specific amount of leakage inductance so an accurate modeling method for calculating such $L_{l k}$ is necessary.

In the literature, many methods have been reported to assess the leakage inductance of a transformer, based on Finite Element Analysis (FEA) or analytical calculation [21]-[35]. For FEA, computation can be made in $2 \mathrm{D}, 3 \mathrm{D}$, or mixed 2D/3D for HF losses and inductance values [1], [21]-[23]. FEA is a powerful tool to study electromagnetic components but when dealing with optimization, using such tool can be very cumbersome and time consuming. Even if the numerical resolution is becoming faster with last generation computers, time for geometry's description and mesh can also be prohibitive. For magnetic component designers, analytical tool will be prefered, in particular for first design steps, when transformer parameters have to be tuned as desired. Most of the analytical methods for the $L_{l k}$ calculation of a transformer are based on 1D Dowell's assumption [24] such that the magnetic flux is tangential to the surface of conductors [25][31]. This assumption is true when the magnetic window is well filled with long conductors. However, in some cases, the winding arrangement may be very irregular such as low filling factor and non-alignment of conductors. Applying the Dowell's assumption will lead to errors in the results. To be more general, the method of Roth can be applied for 2D transformer's winding cross section. This method consists in using double Fourier series to solve the Poisson's equations in a rectangular region [36]. However, double Fourier series exhibit a low convergence rate so that they are computationally expensive. Besides, this method only works when the matter in the rectangular region is uniform. For planar components 


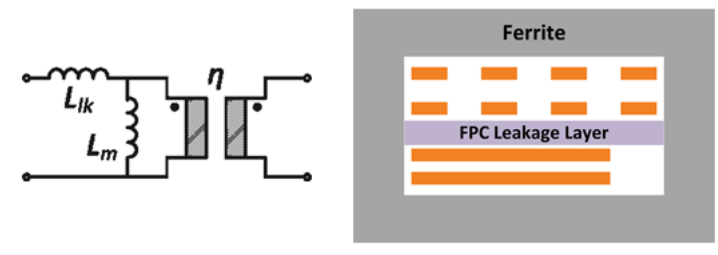

(a)

(b)

Fig. 1. Integrated planar LLC. (a) Equivalent circuit. (b) Cross-section of the component.

whose cross-sections are not magnetically homogeneous, like in the case of leakage layers, Roth's method can not be applied. In such cases, only FEA are performed to determine the value of the leakage inductance [2]. No analytical formulation is available in the literature, except in [37] where some reluctance model is used. This method is still limited to magnetic window well filled with long conductors.

In [38] and [39], authors propose a general 2D analytical method for calculating the leakage inductance of planar transformers. This method is based on a PEEC-like formula for rectangular conductors. To account for the influence of magnetic core, the method of magnetic images is employed on the cross-section of the winding part inside the core [40], [41]. This general method, completely independent of the conductor's arrangement, can accurately evaluate the magnetic field in the cross-section of the component for conventional power electronic transformers, planar ones or more recently for power transformers [42]. However, similarly to Roth's method, the PEEC-like formula also requires a uniform environment of matter as prior condition.

If the cross-sections are magnetically multi-layered, the application of such method can be very cumbersome. For the above reasons, an improved method based on multilayered Green's function has been developed in this paper for calculating the leakage inductance of planar components having magnetically multi-layered structure.

This paper is organized as follows: in Section II, a review of the leakage inductance calculation and the PEEClike formulations are given. Section III introduces the multilayered Green's function with detailed analysis and numerical validations. In Section IV, two application examples, LLC and $\mathrm{CM}$ choke are presented to validate the proposed method. The paper will end with conclusion.

\section{Leakage Calculation Problem Analysis}

\section{A. Modeling of Leakage Inductance}

The existing modeling methods for calculating the static leakage inductance rely on the evaluation of the magnetic energy stored in the component when the total ampere-turns are compensated [43]. The relation between the leakage inductance and the magnetic energy $W_{m a g}$ is expressed by:

$$
W_{m a g}=\frac{1}{2} L_{l k} I^{2} .
$$

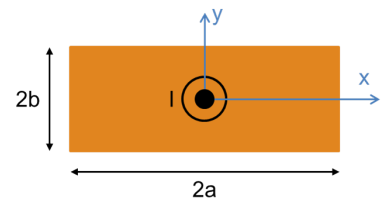

Fig. 2. Rectangular conductor cross-section.

where $L_{l k}$ is the static leakage inductance and $I$ the current in the winding. This magnetic energy $W_{\text {mag }}$ (1) can be determined by 2D or 3D finite element simulations (FEM), which are precise but very time-consuming or with analytical approaches. This computation is generally based on 2D approximation that the current direction is perpendicular to the cross-section of the studied component. Consequently, the magnetic energy $W_{\text {mag }}$ can be calculated by:

$$
W_{\text {mag }}=W s_{\text {mag }} L_{\text {mean }}
$$

where $W s_{\text {mag }}$ is the energy per unit length stored in the cross-section of the studied component whereas $L_{\text {mean }}$ is the mean length of the winding fixed from the location of the peak energy density.

In High Frequency (HF), it is well known that the leakage inductance value will decrease due to eddy current effects [34], [35]. In this work, impact of HF magnetic fields on leakage inductances will not be studied. Indeed, the goal of the developped Green analytic tool is to give designers a fast estimation of their leakage value, as well as in [39]. If this static value does not seem sufficient, the design has to be started again because in HF, leakage will be further reduced.

\section{B. Review of 2D PEEC-like Modeling Method}

In $2 \mathrm{D}$ magnetostatic analysis, the magnetic field over the cross-section of a planar component is governed by the following Poisson's equation:

$$
\nabla^{2} A_{z}=-\mu J_{z}
$$

In order to solve this equation, authors proposed in [38], [39] the 2D PEEC-like formulations, where the leakage inductance of planar transformers can be calculated analytically with no hypothesis on the conductors' topology. In free space, the potential vector $A_{z}$ in the space due to a rectangular conductor carrying current $I$ (Fig. 2) can be expressed by (4).

With this analytical formula, the distribution of the potential vector in the space due to the rectangular conductor can be determined. In case of multiple conductors, the superposition principle can be applied for the calculation. As long as the information of $A_{z}$ is obtained, the integration (5) can be performed to calculate the magnetic energy per unit length stored in the cross-section of the component.

$$
W s_{\text {mag }}=\frac{1}{2} \iint_{\Omega} A_{z} J_{z} d x d y
$$

Thus, the leakage inductance of the component can be estimated by: 


$$
L_{l k} \approx \frac{2 W s_{m a g} L_{m e a n}}{I^{2}}
$$

This method is general and gives accurate estimation of the leakage inductance value. However, just as stated in the introduction, this method can not be applied for multi-layered structure where the permeability of the window is not uniform. Although the magnetic image method [40], [41] can applied for taking into account the influence of magnetic material, it can not be applied on a multi-layered structure where a ferrite polymer layer is present, for the following reasons:

1) With this method, four first-order images are employed due to direct reflections and four second-order images are added due to secondary reflections [39]. Higher order images are neglected. However, when FPC layer is implemented in the region, the reflection phenomenon becomes much more complicated.

2) The aforementioned method assumes that the thickness of the ferrite is infinite. As long as the permeability of the ferrite material is large enough, this assumption is very close to the reality. However, since the FPC layer has a low permeability, the impact of its thickness has to be considered, which further complicates the calculation.

In view of these reasons, an analytical method for leakage inductance calculation based on Green's function for multilayered structure is introduced.

\section{Multi-LAyered Green's Function}

\section{A. Description of the Problem}

The structure of planar components with PCB technology is shown in Fig. 1(b). The leakage layer in ferrite polymer composite is optional but can be used to increase the leakage inductance for passive component integration in the application of soft-switching converters or integrated CM and DM inductors for EMI filters. It should be noted that the FR-4 epoxy and the isolating layers are considered as magnetically transparent. As a consequence, the component cross-section is composed of three layers of matter, i.e. transparent-FPCtransparent. Similarly to [38], the current is supposed to be perpendicular to this cross-section and the system is described by the magnetostatic Poisson's equation (3). As the relative permeability of $\mathrm{MnZn}$ ferrite material is very high (in order of $10^{3}-10^{4}$ ), it can be considered as magnetic material with infinite permeability as an approximation. It can be shown that the boundary conditions (8) holds by using the continuity conditions on the tangential component of the magnetic field $H$ (Fig. 3):

$$
H_{\text {ferrite }}^{T}-H_{\text {window }}^{T}=0
$$

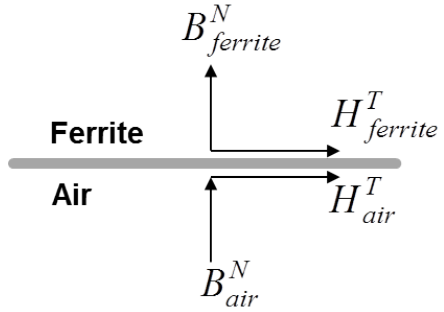

Fig. 3. Continuity conditions on the boundary in the core window.

The boundary conditions for the problem are derived as follows:

$$
\left\{\begin{array}{l}
\frac{\partial A_{z}}{\partial y}=0 \text { over the horizontal surface } \\
\frac{\partial A_{z}}{\partial x}=0 \text { over the vertical surface }
\end{array}\right.
$$

As seen, homogeneous Neumann boundary conditions are obtained. However, this problem admits solutions if and only if the compatibility condition is satisfied:

$$
\int_{\partial \Omega} \frac{\partial A_{z}}{\partial n} d l+\mu_{0} \int_{\Omega} J_{z} d S=0
$$

This can be proved by applying Gauss's Law on the Poisson's equation (3). With the homogeneous boundary conditions (8), the first term of equation (9) is null, requiring the second term to be null too. In fact, this is the prior condition for the calculation of leakage inductance. Therefore, the Poisson's equation (3) with these boundary conditions admit solutions.

After solving the potential vector $A_{z}$ from (9), the equation (5) and (6) should be used to determine the leakage inductance of such component.

\section{B. Generality on Green's Function}

Green's function is a powerful tool for analyzing electromagnetic problems. It is a specially constructed function to solve partial differential equations [44]. It can be regarded as the impulse response of an electromagnetic system to Dirac type excitation. For the magnetostatic Poisson's equation given in (3), its associated Green's function is:

$$
\nabla^{2} G=-\mu \delta
$$

where $\delta$ is a Dirac current source. With this Green's function, the solution of the original problem can be expressed by:

$$
A_{z}(x, y)=\int_{\Omega} G(x, y) J_{z} d S-\frac{1}{\mu} \oint_{\partial \Omega} A_{z} \frac{\partial G}{\partial n} d l
$$

$$
A_{z}(x, y ; a, b)=\left.\frac{-\mu_{0} I}{16 \pi a b}\left[X Y \ln \left(X^{2}+Y^{2}\right)+X^{2} \arctan \left(\frac{Y}{X}\right)+\left.Y^{2} \arctan \left(\frac{X}{Y}\right)\right|_{X=x+a} ^{X=x-a}\right]\right|_{Y=y+b} ^{Y=y-b}
$$


From this equation, it is desirable to also provide homogeneous Neumann boundary conditions for the Green's function so that the second term of (11) is null and the potential vector $A_{z}$ can be represented by a convolution. However, this is not allowed since such boundary condition will violate the compatibility condition. Indeed, the following compatibility condition should be satisfied during the construction of the Green's function:

$$
\int_{\partial \Omega} \frac{\partial G}{\partial n} d l=-\mu_{0}
$$

\section{Multi-layered Green's Function}

In [45], [46], authors present a multi-layered Green's function for solving electrostatic Poisson's equation with homogeneous Dirichlet boundary conditions in a bounded multilayered region. As stated previously, the studied planar components have a magnetically multi-layered cross-section. In this paper, the method of [45] will be extended for magnetostatic analysis. It has been shown that the boundary conditions should verify (8) to admit solutions. Therefore, the following boundary conditions are proposed:

$$
\left\{\begin{array}{l}
\left.\frac{\partial G}{\partial y}\right|_{y=H}=-\frac{\mu_{0}}{L} \\
\left.\frac{\partial G}{\partial x}\right|_{x=0}=\left.\frac{\partial G}{\partial x}\right|_{x=L}=\left.\frac{\partial G}{\partial y}\right|_{y=0}=0
\end{array}\right.
$$

As seen, only the top edge of the rectangular region is not zero. With these boundary conditions, the compatibility conditions given in (12) can be satisfied.

According to the previous analysis, the cross-section of the planar component is a 3-layer structure. If a Dirac current source is introduced, the structure is further split into four layers. Therefore, only a 4-layer structure is studied in this work. As shown in Fig. 4(a), each layer has a height $H_{k}$ and a permeability $\mu_{k}$. Here, the local coordinates are applied for each layer and the origin is chosen at the lower left vertex of each rectangular region. The Dirac current source locates at the interface between layer $j$ and $j+1(j<4)$. As a consequence, the Green's function in layer $i$ satisfies:

$$
\nabla^{2} G^{i}=0
$$

The following boundary conditions can be written out:

1) Left and right boundaries of layer $i: x=0$ and $x=L$ :

$$
\left.\frac{\partial G^{i}}{\partial x}\right|_{x=0}=\left.\frac{\partial G^{i}}{\partial x}\right|_{x=L}=0
$$

2) Top and bottom boundaries (in layer 4 and layer 1):

$$
\begin{cases}\left.\frac{\partial G^{1}}{\partial y}\right|_{y=0}=0 & \text { Layer } 1 \\ \left.\frac{\partial G^{4}}{\partial y}\right|_{y=H_{4}}=-\frac{\mu_{0}}{L} & \text { Layer } 4\end{cases}
$$

3) Continuity conditions on the interface between layer $i$

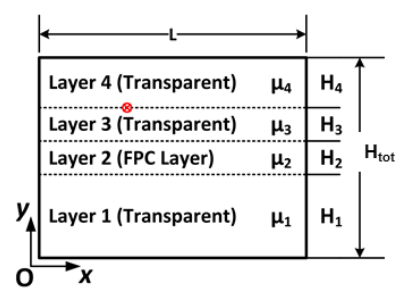

(a)

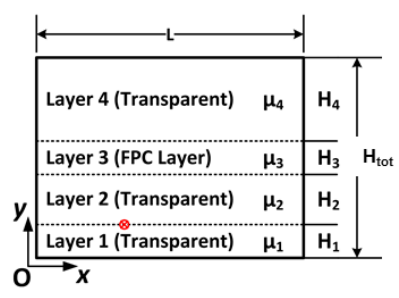

(b)
Fig. 4. 4-layer structure for Green's function deduction. (a) Source point higher than FPC layer. (b) Source point lower than FPC Layer.

$$
\begin{aligned}
& \text { and } i+1(i<4) \text { : } \\
& \left\{\begin{array}{l}
\left.G^{i}\right|_{y=H_{i}}-\left.G^{i+1}\right|_{y=0}=0 \\
\left.\frac{1}{\mu_{i}} \frac{\partial G^{i}}{\partial y}\right|_{y=H_{i}}-\left.\frac{1}{\mu_{i+1}} \frac{\partial G^{i+1}}{\partial y}\right|_{y=0}=\delta_{i j} \delta\left(x-x_{s}\right)
\end{array}\right.
\end{aligned}
$$

where $\delta_{i j}$ is the Chronecker Delta function whereas $\delta(x-$ $x_{s}$ ) presents the Dirac current source.

From these boundary conditions (15), the general solution in layer $i$ can be derived as follows:

$$
G^{i}=\alpha_{0}^{i} y+\beta_{0}^{i}+\sum_{n=1}^{\infty}\left[\alpha_{n}^{i} \operatorname{ch}\left(k_{n} y\right)+\beta_{n}^{i} \operatorname{sh}\left(k_{n} y\right)\right] \cos \left(k_{n} x\right)
$$

where $\operatorname{ch}()$ and $\operatorname{sh}()$ are hyperbolic cosine and sinus functions respectively. Note that the term $\alpha_{0}^{i} y+\beta_{0}^{i}$ appears since the eigenvalue of (14) can be zero [46].

In order to determine the parameters $\alpha_{0}^{i}, \beta_{0}^{i}, \alpha_{n}^{i}$ and $\beta_{n}^{i}$, the remaining boundary conditions are used. From (16), the following relations hold:

$$
\left\{\begin{array}{l}
\alpha_{0}^{1}=0 \quad \text { and } \quad \beta_{n}^{1}=0 \\
\alpha_{0}^{4}=-\frac{\mu_{0}}{L} \quad \text { and } \quad \beta_{n}^{4}=-\alpha_{n}^{4} \tanh \left(k_{n} H_{4}\right)
\end{array}\right.
$$

The next step consists in using the continuity condition (17) to establish the link between the parameters of different layers. The detailed derivation is given in Appendix, only the final results are given here. The parameters $\alpha_{0}^{i}, \beta_{0}^{i}, \alpha_{n}^{i}$ and $\beta_{n}^{i}$ can be expressed by (24). Note that $\left[\mathbf{F}_{n}^{l, l+1}\right]$ and $\left[\mathbf{F}_{n}^{l, l+1}\right]^{-1}$ are the up-going and down-going transformation matrix, respectively:

$$
\begin{gathered}
{\left[\mathbf{F}_{0}^{l, l+1}\right]=\left[\begin{array}{cc}
\frac{\mu_{l+1}}{\mu_{l}} & 0 \\
H_{l} & 1
\end{array}\right]} \\
{\left[\mathbf{F}_{0}^{l, l+1}\right]^{-1}=\left[\begin{array}{cc}
\frac{\mu_{l}}{\mu_{l+1}} & 0 \\
\frac{-\mu_{l}}{\mu_{l+1}} H_{l} & 1
\end{array}\right]} \\
{\left[\mathbf{F}_{n}^{l, l+1}\right]=\left[\begin{array}{cc}
\operatorname{ch}\left(k_{n} H_{l}\right) & \operatorname{sh}\left(k_{n} H_{l}\right) \\
\frac{\mu_{l+1}}{\mu_{l}} \operatorname{sh}\left(k_{n} H_{l}\right) & \frac{\mu_{l+1}}{\mu_{l}} \operatorname{ch}\left(k_{n} H_{l}\right)
\end{array}\right]}
\end{gathered}
$$




$$
\left[\mathbf{F}_{n}^{l, l+1}\right]^{-1}=\left[\begin{array}{cc}
\operatorname{ch}\left(k_{n} H_{l}\right) & -\frac{\mu_{l}}{\mu_{l+1}} \operatorname{sh}\left(k_{n} H_{l}\right) \\
-\operatorname{sh}\left(k_{n} H_{l}\right) & \frac{\mu_{l}}{\mu_{l+1}} \operatorname{ch}\left(k_{n} H_{l}\right)
\end{array}\right]
$$

The parameter $\alpha_{n}^{1}$ and $\alpha_{n}^{4}$ can be derived from the continuity condition when $i=j$.

\section{Magnetic Field Calculation}

The first integral can be performed on the conductor area where the current is non-zero. The second term corresponds to the average value of the potential vector on the boundary of the region, which is a constant. Neglecting this constant, the first integral of (11) can be evaluated analytically [due to the term $\cos \left(k_{n} x_{s}\right)$ in (25)] along $x$-axis and numerically along $y$-axis by discretizing the conductor into $K$ thin elements (Fig.5). For element $k$, the $y$ coordinate of the center point $y_{s m}=$ $\left(y_{k}+y_{k+1}\right) / 2$ is chosen for the integration along $y$-axis.

The magnetic induction $B$ can then be calculated by deriving $A_{z}$, as given by (26). Note that the parameters $\alpha_{0}^{i}, \beta_{0}^{i}, \alpha_{n}^{i}$ and $\beta_{n}^{i}$ are only dependent to the coordinate of the source point. This property allows the separation of the mathematical treatment on the source conductor and the observation one. Therefore, the partial derivation on $G$ (on the observation point) given in (26) can be performed directly on the expression whereas the integration on the source conductor is still evaluated numerically as done before.

$$
\left\{\begin{array}{l}
B_{x}=\frac{\partial A_{z}}{\partial y}=-\mu \int_{\Omega} \frac{\partial G(x, y)}{\partial y} J d s \\
B_{y}=-\frac{\partial A_{z}}{\partial x}=\mu \int_{\Omega} \frac{\partial G(x, y)}{\partial x} J d s
\end{array}\right.
$$

The final purpose involves estimating the total energy in the cross-section via the integral (5). The Greens function has to be integrated both on the source conductor and the observation conductor. The integration on the source conductor is performed numerically while the integration on the observation conductor can be performed analytically according to the expression (18). However, three cases should be distinguished (Fig. 6):

1) The position of the source conductor element is higher than the observation conductor:

In this case, the observation conductor is completely in layer $i+1$, therefore the integration is performed with the Greens function $G^{i+1}$ for layer $i+1$.

2) The position of the source conductor element is lower than the observation conductor:

In this case, the observation conductor is completely in layer $i$, the integration is thereby calculated with the Greens function $G^{i}$ for layer $i$.

3) The position of the source conductor element is included in the observation conductor:

In this case, as the observation conductor crosses the two layers, the integration is performed by two separate parts. Both the Greens function $G^{i}$ and $G^{i+1}$ should be integrated on the corresponding parts.

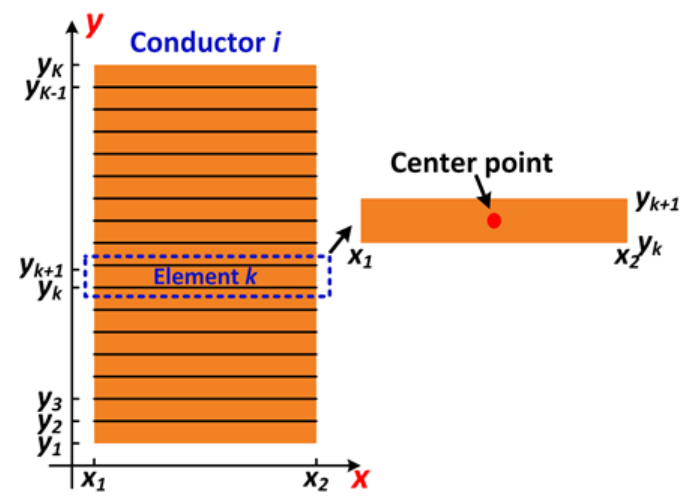

Fig. 5. Discretization along $y$-axis of the source conductor.

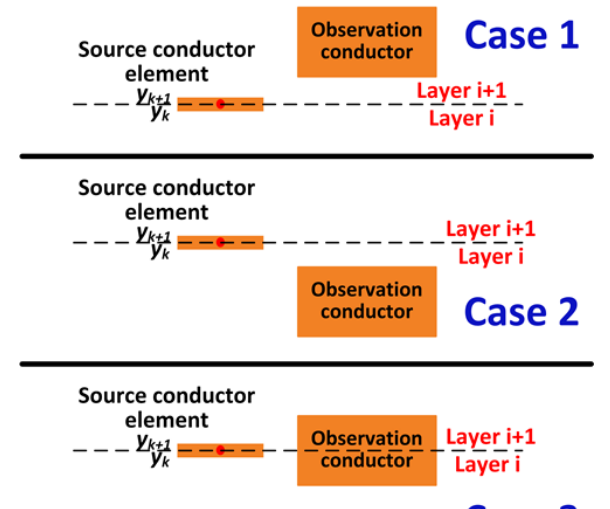

Case 3

Fig. 6. Analytical integration on the observation conductor: Three cases.

Note that during the calculation of $A_{z}$, a constant appears on the final obtained results due to the Neumann type boundary conditions [47]. However, this constant will not affect the results of (5) since the integral of this constant over all the conductors will be null as the total ampere-turns is compensated in the component's window.

\section{E. Numerical Validations}

To validate the proposed method, the multi-layered Green's function is applied on two structures. The first case (Fig. 7) does not correspond to real component but is computed to test the developped approach. The second one, is closer to a real planar component (Fig. 10(a)). For both components, numerical simulations, performed with ANSYS Maxwell 2D [48], are done to be compared to Green's calculation. For each FEA simulation, total ampere-turns are compensated.

1) Configuration test: As shown in Fig. 7, an FPC layer is implemented so that the structure is divided into three layers. The total ampere-turns of the component are compensated. To analyse the results, two test cuts are performed on this crosssection at $y=0.75 \mathrm{~mm}$ and $y=3.75 \mathrm{~mm}$ respectively. The obtained vector potential on these two test cuts are compared with Finite Elements simulations results, as shown in Fig. 8(a). As seen, a constant difference is observed between the calculated curves and the simulated ones. These results 


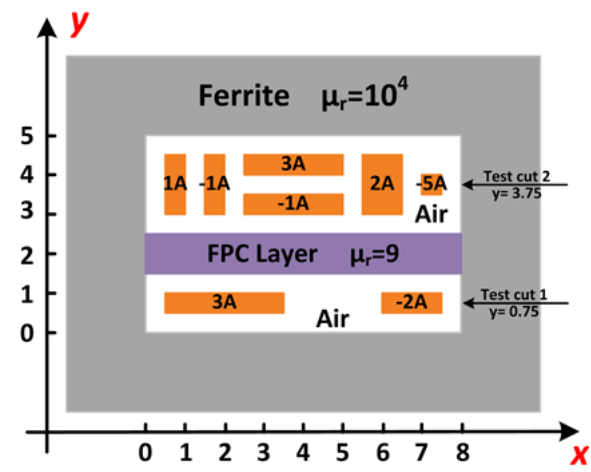

Fig. 7. Test configuration.

are foreseen due to the Neumann type boundary conditions. Removing this constant (Fig. 8(b)), a good agreement between these two curves can be found. The magnetic induction $B_{x}$ and $B_{y}$ can also be deduced, as illustrated in Fig. 9. One can note a good coherence between the calculated curves and simulated ones. After the numerical integration, the magnetic energy stored in the window is $2.29 E-5 \mathrm{~J} / \mathrm{m}$ while the calculated one is similar. In the previous analysis, it is supposed that the permeability is infinite. Indeed, even though the practical permeability of ferrite material is in the order of $10^{3} \mu_{0}$, the infinite-permeability assumption still gives good approximation to the reality. FEA simulations have been performed to assess the influence of the magnetic core. Results are presented in Table I where the magnetic energy stored in the windows is computed with various permeability values. Comparing FEA results and the Green's calculations, it can be seen that the proposed method can accurately determine the magnetic field in the structures of interest.

2) Planar CM choke: This second test case is based on the design of a planar CM choke (Fig. 10(a)) made of 3F3 E32/I planar core [49]. Some FPC layer (height $0.8 \mathrm{~mm}$ ) is added between two windings. The total ampere-turns of the component are also compensated. The current in each conductor higher than the FPC layer is $-1 A$ whereas the current is $1 A$ for the conductors lower than the FPC layer. The Fig 10(b) shows the magnetic field inside the component's window. From this simulation, it can be concluded that the field is not tangential to the conductors. Therefore, the 1D

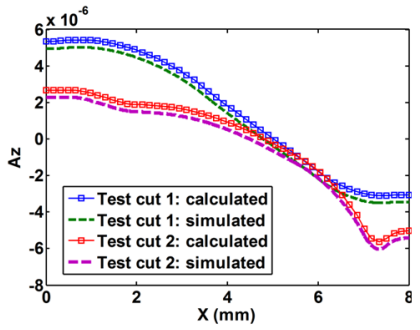

(a)

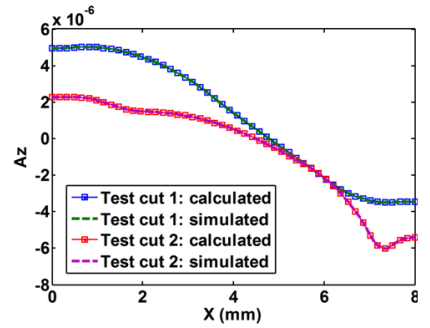

(b)
Fig. 8. Comparison between calculated results and simulated results. (a) Before removing the constant. (b) After removing the constant.

Dowell assumption is not directly applicable in such case. This hypothesis is confirmed when analysing $B x$ and $B y$ (Fig. 11) along the horizontal test cut at $H=1.5 \mathrm{~mm}$. Simulated results are also compared to the computed ones in Fig. 11, where both simulated and calculated fields show good agreement.

After numerical integration, the calculated magnetic energy stored in the window is $2.43 E-5 J / m$, while the simulated value is $2.57 E-5 \mathrm{~J} / \mathrm{m}$. The difference is equal only to $5 \%$.

\section{APPLICATIONS}

The previous method has been tested on two real components: A LLC transformer and a CM choke. Both devices are based on the use of ferrite planar cores [49], associated with FPC C350 [50] for the leakage layers.

\section{A. Components' description}

For the LLC transformer (Fig. 12(a)), two 3F3 E38-cores are used while for the CM inductor (Fig. 13(a)), two 3C90 E43-cores are preferred.

The transformer is made of 4 copper layers of $35 \mu \mathrm{m}$ with 8 turns for the primary and 2 for the secondary. The CM inductor is a symmetrical component, made of 8 identical $70 \mu \mathrm{m}$ copper layers with 4 turns on each layer. For both components a leakage layer made of FPC is sandwiched between the two windings to increase the leakage inductance. This FPC layer is set to $0.2 \mathrm{~mm}$ and $0.96 \mathrm{~mm}$, for the transformer and the CM inductor, respectively. The winding arrangements are described in Fig.12(b) and Fig.13(c).

$$
\begin{aligned}
& {\left[\begin{array}{l}
\alpha_{0}^{i} \\
\beta_{0}^{i}
\end{array}\right]=\left\{\begin{array}{l}
{\left[\begin{array}{c}
0 \\
0
\end{array}\right]} \\
{\left[\prod_{l=i}^{N-1}\left[\mathbf{F}_{0}^{l, l+1}\right]^{-1}\right]\left[\begin{array}{c}
\left.-\frac{\mu_{0}}{L}\right] \\
0
\end{array}\right] \quad i>j}
\end{array} \quad \text { and }\left[\begin{array}{c}
\alpha_{n}^{i} \\
\beta_{n}^{i}
\end{array}\right]=\left\{\begin{array}{c}
\left.\left[\begin{array}{c}
1 \\
\left.\prod_{l=i-1}\left[\mathbf{F}_{n}^{l, l+1}\right]\right]
\end{array}\right] \begin{array}{c}
\alpha_{n}^{1} \\
0
\end{array}\right] \\
{\left[\prod_{l=i}^{N-1}\left[\mathbf{F}_{n}^{l, l+1}\right]^{-1}\right]\left[\begin{array}{c}
\alpha_{n}^{4} \\
-\alpha_{n}^{4} \tanh \left(k_{n} H_{4}\right)
\end{array}\right] \quad i>j}
\end{array}\right.\right.} \\
& \left\{\begin{array}{l}
\prod_{l=3}^{j}\left[\mathbf{F}_{0}^{l, l+1}\right]^{-1}\left[\begin{array}{c}
-\frac{\mu_{0}}{L} \\
\beta_{0}^{4}
\end{array}\right]=\prod_{l=1}^{j}\left[\mathbf{F}_{0}^{l, l+1}\right]\left[\begin{array}{c}
0 \\
\beta_{0}^{1}
\end{array}\right]+\left[\begin{array}{c}
-\frac{\mu_{j+1}}{L} \\
0
\end{array}\right] \\
\prod_{l=3}^{j}\left[\mathbf{F}_{n}^{l, l+1}\right]^{-1}\left[\begin{array}{c}
\alpha_{n}^{4} \\
-\alpha_{n}^{4} \tanh \left(k_{n} H_{4}\right)
\end{array}\right]=\prod_{l=1}^{j}\left[\mathbf{F}_{n}^{l, l+1}\right]\left[\begin{array}{c}
\alpha_{n}^{1} \\
0
\end{array}\right]+\left[\begin{array}{c}
0 \\
-\frac{2 \mu_{j+1}}{n \pi} \cos \left(k_{n} x_{s}\right)
\end{array}\right]
\end{array}\right.
\end{aligned}
$$


TABLE I

VARIation of Magnetic ENERgy with Permeability

\begin{tabular}{c|c|c|c|c|c}
\hline \hline$\mu_{r}$ & $\infty$ & 10000 & 5000 & 1000 & 500 \\
\hline$W s_{\text {mag }}(\mathrm{J} / \mathrm{m})$ & $2.29 \mathrm{E}-5$ & $2.29 \mathrm{E}-5$ & $2.29 \mathrm{E}-5$ & $2.28 \mathrm{E}-5$ & $2.27 \mathrm{E}-5$ \\
\hline \hline
\end{tabular}
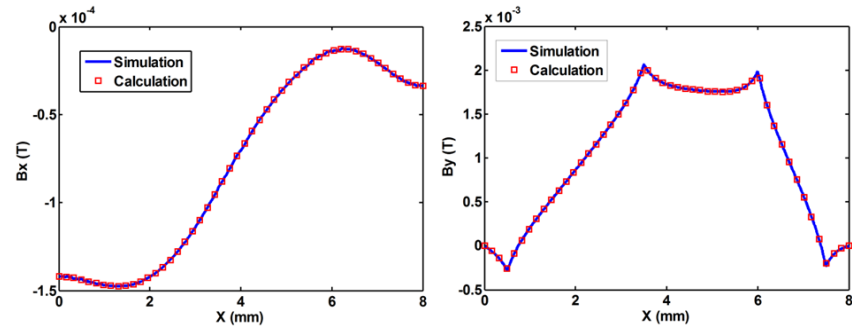

(a)

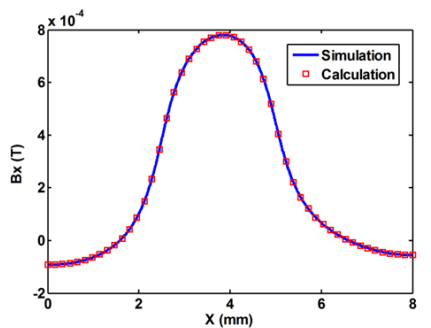

(c) (b)

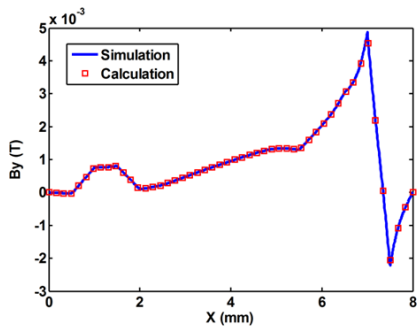

(d)

Fig. 9. Comparison between calculated results and simulated results for the test case. (a) Test cut $1: B_{x}$. (b) Test cut $1: B_{y}$. (c) Test cut 2: $B_{x}$. (d) Test cut 2: $B_{y}$

\section{B. Leakage inductance calculation}

For the part inside the core, the previous Green's computation is applied. For the winding part outside the core, the FPC layer is not implemented. Therefore, the PEEC-like formulations can be employed for calculating the magnetic field as well as the magnetic energy per unit length. In fact, it can be shown that the PEEC-like formula (4) is the integral form of the free space Green's function (Green's theorem) over the rectangular region $[-a / 2, a / 2] \times[-b / 2, b / 2][51]$ :

$$
G\left(x, y ; x_{s}, y_{s}\right)=-\frac{\mu_{0}}{2 \pi} \ln \sqrt{\left(x-x_{s}\right)^{2}+\left(y-y_{s}\right)^{2}}
$$

The Table II presents energy computed inside the core using Green's functions $W_{i c}$ and the one calculated outside the core based on PEEC formulas $W_{o c}$. The total leakage inductance is then calculated with (28) taking into account lengths of windings inside and outside the core (Fig. 14). For the LLC transformer, the leakage inductance is evaluated to $162 \mathrm{nH}$ while for the CM inductor, it is equal to $13.4 \mu \mathrm{H}$.

$$
L_{l k}=\frac{2}{I^{2}}\left[2 W_{i c} l_{i c}+W_{o c}\left(l_{o c 1}+l_{o c 2}\right)\right]
$$

Regarding computation time, duration depends on the number of conductors. For example, the LLC computation lasts $3.45 \mathrm{~s}$ while the CM inductor $5.14 \mathrm{~s}$. As a comparison, FEA performed on the example of Fig. 10(a) lasts 15s. Such semi-

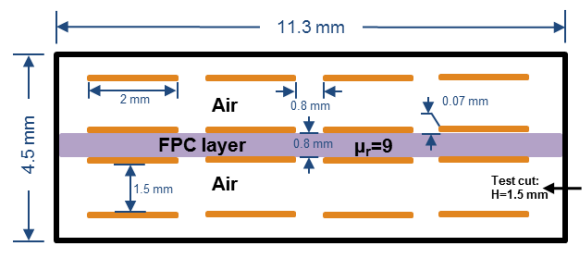

(a)

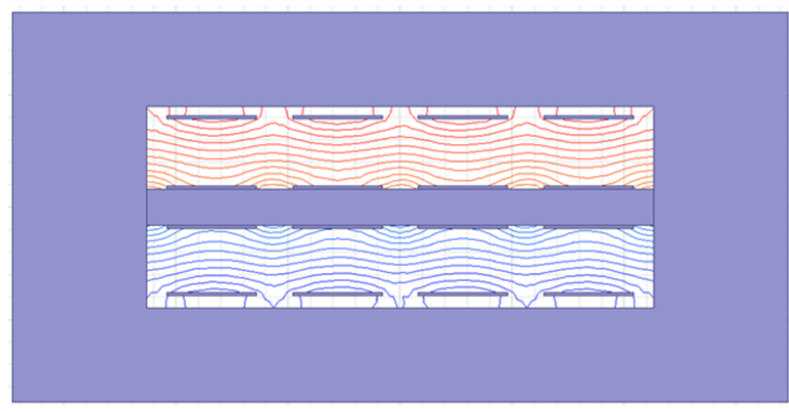

(b)

Fig. 10. Planar CM choke cross section under simulation. (a) Window cross section. (b) Field inside the window.

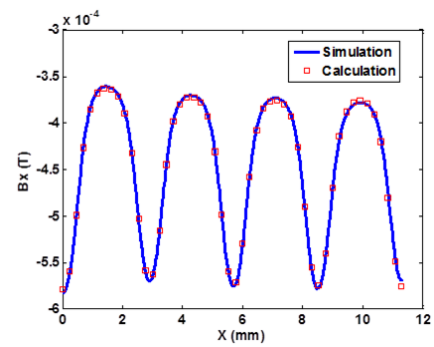

(a)

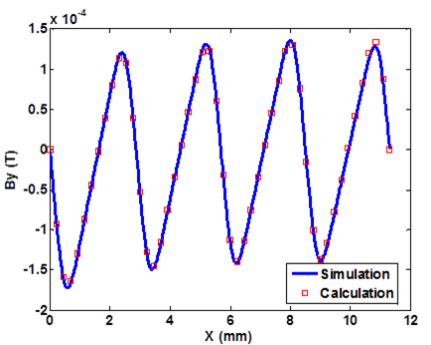

(b)
Fig. 11. Comparison between calculated results and simulated results. (a) Test cut: Bx. (b) Test cut: By.

analytical approach can then be interesting for component's optimization and its leakage inductance tuning.

\section{Leakage inductance measurement}

Both components are then characterized with an impedance analyzer [52] and their leakage inductances are measured based on method proposed in [53]: The leakage impedance $Z_{s}$ (Fig. 15) is calculated using open-circuit and short-circuit impedance measurements (29). This method enables to cancel the effect on magnetizing inductance while calculating the leakage one (30).

$$
Z_{s}=\frac{Z_{0}{ }^{\prime}\left(Z_{c c}-r_{p}\right)}{\left(Z_{0}-r_{p}\right)-r_{s}}
$$




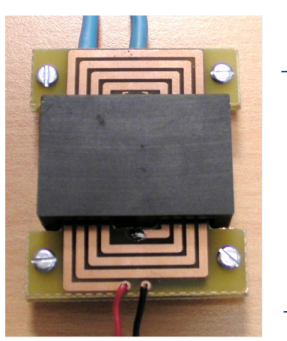

(a)

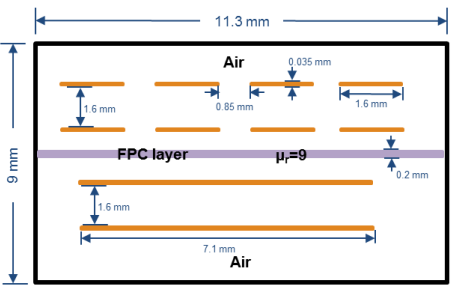

(b)

Fig. 12. LLC planar transformer (a) Component top view. (b) Cross section and dimensions.

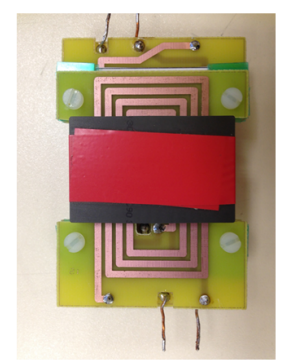

(a)

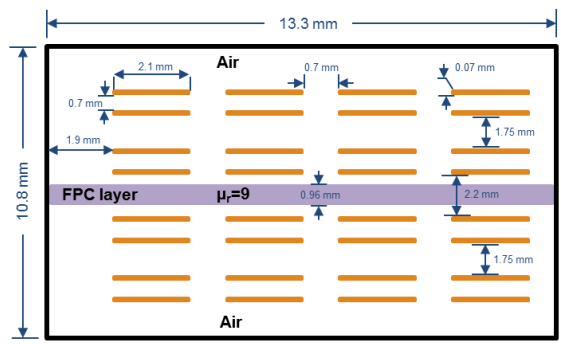

(c)

Fig. 13. Planar CM choke. (a) Component Top view. (b) Component Face view. (c) Cross section and dimensions

with $Z_{0}$ the impedance measured from primary winding with secondary in open-circuit, $Z_{0}{ }^{\prime}$ the impedance measured from secondary winding with primary in open-circuit and $Z_{c c}$ the impedance measured from primary winding with secondary in short-circuit. $r_{p}$ (Fig.15) is deduced from $Z_{0}$ in low frequency while $r_{s}$ is calculated with $Z_{0}^{\prime}$ also in low frequency [53].

TABLE II

LEAKAGE INDUCTANCE CALCULATION

\begin{tabular}{c|c|c}
\hline \hline Component & LLC & CM ind \\
\hline Core type & E38 & E43 \\
\hline Mag. material & $3 \mathrm{~F} 3$ & $3 \mathrm{C} 90$ \\
\hline$l_{i c}(\mathrm{~m})$ & $25.4 E-3$ & $27.9 E-3$ \\
\hline$l_{o c 1}+l_{o c 2}(\mathrm{~m})$ & $30 E-3$ & $88 E-3$ \\
\hline$W_{i c}(\mathrm{~J} / \mathrm{m})$ & $1.009 E-6$ & $6.691 E-5$ \\
\hline$W_{o c}(\mathrm{~J} / \mathrm{m})$ & $5.007 E-7$ & $3.367 E-5$ \\
\hline$L_{l k}(\mathrm{H})$ & $162 E-9$ & $13.4 E-6$ \\
\hline \hline
\end{tabular}

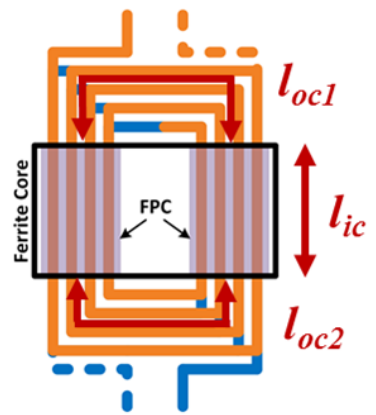

Fig. 14. Typical winding length.

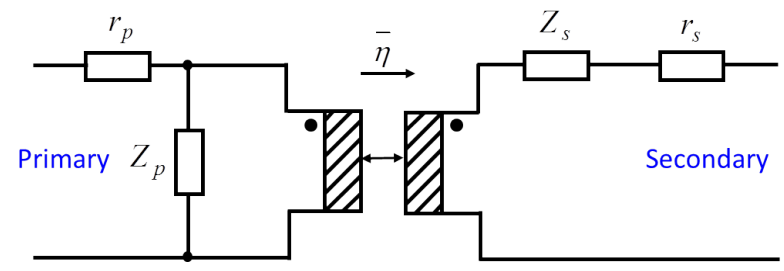

Fig. 15. Equivalent circuit for leakage measurement.

$$
L_{l k_{\text {meas }}}=\operatorname{Im}\left(\frac{Z_{s}}{2 \pi f}\right)
$$

The measured values are plotted in Fig. 16, where they are compared to the computed ones. In this figure, for low frequencies, the leakage inductance is masked by resistances while in HF, parasitic capacitances cancel the magnetic effect. The leakage value is quite constant on the frequency range $[1 k H z ; 1 M H z]$.

In both components coupling coefficients $k$ between windings are close to 1 . Magnetizing inductances are evaluated to $431 \mu \mathrm{H}$ and $851 \mu \mathrm{H}$ for the LLC and the CM inductor, respectively. These values are widely stronger than the leakage ones. With such a difference, the total ampere-turn compensation hypothesis stays valid because magnetizing current can be neglected in case of short-circuit test.

\section{Discussion}

Regarding Fig. 16, it can be noted that computation for both cases gives good result with error lower than $15 \%$. These differences can be justified for following reasons:

1) Errors related with dimensions: The dimensions reported in Fig. 12(b) and Fig. 13(c) have been measured directly on the prototypes and are not precises.

2) Simplification of the geometry: The window's description is not identical inside and outside the core. The part inside the magnetic core is well described but the one outside is simplified and the angles/corners are not really taken into account.

3) Sensitivity to the average length: The results are directly proportional to the energy density. They have to be multiplied by a lenght which is easy to determine inside the core (depth of the core) but which is more difficult 
to evaluate outside. A mean path is fixed, based on window's peak energy but this assumption is not precise.

4) Magnetic material disparities: As an example, the C 350 material is given with a permeability of $9 \pm 20 \%$ [50]. The same computation has been done again, taking into account this disparity. Calculation has been done with $\mu_{r}=10.8(9+20 \%)$ and $\mu_{r}=7.2(9-20 \%)$. The Table III summarizes the results and shows that this parameter can lead to significant differences.

Without the leakage layers, leakage inductance can be evaluated, based on [39], to $128 \mathrm{nH}\left(W_{i c}=6.68 \mathrm{E}-7 \mathrm{~J} / \mathrm{m}\right)$ and $11.8 \mu \mathrm{H}\left(W_{i c}=5.287 E-5 \mathrm{~J} / \mathrm{m}\right)$ for the LLC transformer and the $\mathrm{CM}$ inductor, respectively. The leakage layers enable then to increase the leakage inductance and can be analytically calculated with a good precision with the developped method. However, this increase can be considered as quite low while regarding relative differences between leakage inductances with and without leakage layers. As a percentage, this rise is equal to $26 \%$ for the LLC and $13 \%$ for the CM inductor. These values can still be increased by acting on two main factors:

1) Increase of FPC thickness: In both examples, FPC layers are limited to $0.2 \mathrm{~mm}$ and $0.96 \mathrm{~mm}$. Adding some layers, can enable to increase the leakage inductance value.

2) Addition of FPC outside the core: In this work, only FPC inside the core was considered. Adding leakage layers outside the core will also increase the leakage value. But the present method will not be able to calculate its value. Only 3D FEA could be performed to do this assessment.

These both solutions can also be discussed. Indeed, in most of power electronic converters, while power density is required, HF power transformers are made of interleaved layers to limit HF copper losses [54], [55]. Such interleaving reduces the leakage inductance. FPC can be added between each primary and secondary layers [56] but here also, the present method will be unusable. Some developpements have to be made on massively multi-layered windings as well as HF effects.

In connection with HF power transformers, problem of parallel windings should also be adressed. In planar transformers, parallel layers are a common practice to increase currents inside windings. The Green method can be applied with such conductor configurations. Indeed, only current values have to be settled, as in the example presented in Fig.7. In low frequency, the current repartition will be homogeneous and current will be uniformly distributed inside conductors. It is not true in HF, but the developped Green method is also limited and can not be applied in HF.

\section{CONClusion}

In this paper, the leakage inductance of planar magnetic components including leakage layer is studied via an analytical method based on multilayered Green's function. Using this Green's function, the Poisson equation for a rectangular region with Neumanns type boundary conditions can be solved to determine the magnetic field in the cross-section of the studied component. Simulation and measurement results show that this

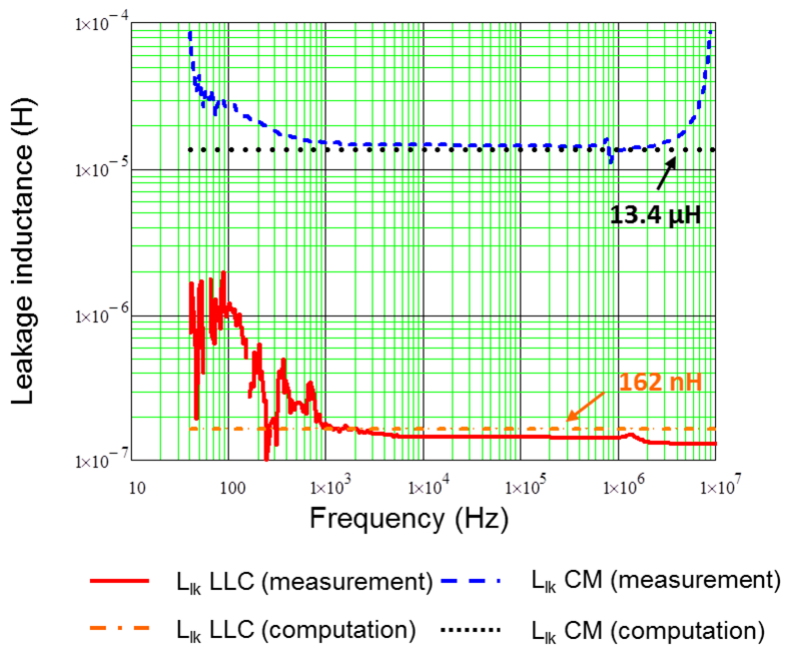

Fig. 16. Comparison between measurement and computation results.

method is very effective and accurate for planar component leakage inductance calculation when a leakage layer is inserted inside the component's windings.

\section{APPENDIX A \\ DERIVATION OF EQUATION}

Recall the general solution of Greens function in layer $i$ (18) and the continuity condition (17). If $i \neq j, \delta_{i j}=0$. In this case, the Dirac current source does not locate on the interface to analyze. The condition can be expressed by (31). Based on the equality of the coefficients term by term, the following matrix systems can be derived:

$$
\left[\begin{array}{c}
\alpha_{n}^{i+1} \\
\beta_{n}^{i+1}
\end{array}\right]=\left[\mathbf{F}_{n}^{i, i+1}\right]\left[\begin{array}{c}
\alpha_{n}^{i} \\
\beta_{n}^{i}
\end{array}\right] \quad(n=0,1,2 \ldots \infty)
$$

Here the matrix $\left[\mathbf{F}_{n}^{i, i+1}\right]$ is the upward transformation matrix that relates the parameters of layer $i$ and layer $i+1$. Its expression can be found in (20) and (22). The downward transformation matrix $\left[\mathbf{F}_{n}^{i, i+1}\right]^{-1}$ can be defined similarly as:

$$
\left[\begin{array}{c}
\alpha_{n}^{i} \\
\beta_{n}^{i}
\end{array}\right]=\left[\mathbf{F}_{n}^{i, i+1}\right]^{-1}\left[\begin{array}{c}
\alpha_{n}^{i+1} \\
\beta_{n}^{i+1}
\end{array}\right] \quad(n=0,1,2 \ldots \infty)
$$

where $\left[\mathbf{F}_{n}^{i, i+1}\right]^{-1}$ is given in (21) and (23).

If $i=j, \delta_{i j}=1$. In this case, the Dirac current source locates on the studied interface. The condition (17) becomes (32). Integrate the second term of this equation (32) on $[0, L]$ :

$$
\frac{L}{\mu_{j}} \alpha_{0}^{j}-\frac{L}{\mu_{j+1}} \alpha_{0}^{j+1}=1
$$

Multiply the two sides of the second equation of (32) by $\cos (k n x)$, and integrate it on $[0, L]$ : 
TABLE III

LEAKAGE INDUCTANCE VARIATION

\begin{tabular}{c|c|c|c|c}
\hline \hline & \multicolumn{2}{|c|}{ LLC } & \multicolumn{2}{c}{ CM } \\
\hline & Leakage value & $\begin{array}{c}\text { Error with } \\
\text { measurement }\end{array}$ & Leakage value & $\begin{array}{c}\text { Error with } \\
\text { measurement }\end{array}$ \\
\hline$\mu_{r}=9$ & $162 n H$ & $11.1 \%$ & $13.4 \mu H$ & $8.2 \%$ \\
\hline$\mu_{r}=10.8(+20 \%)$ & $170 n H$ & $15.4 \%$ & $14.7 \mu H$ & $<1 \%$ \\
\hline$\mu_{r}=7.2(-20 \%)$ & $154 n H$ & $6.4 \%$ & $12.1 \mu H$ & $17.1 \%$ \\
\hline \hline
\end{tabular}

$\frac{1}{\mu_{j}} \sum_{n=1}^{\infty}\left[\alpha_{n}^{j} \operatorname{sh}\left(k_{n} H_{j}\right)+\beta_{n}^{j} \operatorname{ch}\left(k_{n} H_{j}\right)\right]-\frac{\beta_{n}^{j+1}}{\mu_{j+1}}=\frac{2 \cos \left(k_{n} x_{s}\right)}{n \pi}$

Rearrange the equation (35), (36) and the first equation of (32), the following matrix system are obtained:

$$
\begin{gathered}
{\left[\begin{array}{l}
\alpha_{0}^{j+1} \\
\beta_{0}^{j+1}
\end{array}\right]=\left[\mathbf{F}_{0}^{j, j+1}\right]\left[\begin{array}{c}
\alpha_{0}^{j} \\
\beta_{0}^{j}
\end{array}\right]+\left[\begin{array}{c}
-\frac{\mu_{j+1}}{L} \\
0
\end{array}\right]} \\
{\left[\begin{array}{c}
\alpha_{n}^{j+1} \\
\beta_{n}^{j+1}
\end{array}\right]=\left[\mathbf{F}_{n}^{j, j+1}\right]\left[\begin{array}{c}
\alpha_{n}^{j} \\
\beta_{n}^{j}
\end{array}\right]+\left[\begin{array}{c}
0 \\
\frac{2 \mu_{j+1}}{-n \pi} \cos \left(k_{n} x_{s}\right)
\end{array}\right]}
\end{gathered}
$$

To solve the value of $\alpha_{0}^{i}, \beta_{0}^{i}, \alpha_{n}^{i}$ and $\beta_{n}^{i}$, the equations (37) and (38) are solved. On the interface between layers $j$ and $j+1$ $(j<4)$, the equations $(25)$ hold. It can be shown that $\beta_{0}^{1}=$ $\beta_{0}^{2}=\beta_{0}^{3}=\beta_{0}^{4}=$ constant , which agree with feature of a homogenous Neumann B.C. problem that an arbitrary constant will appear in the final solutions. In this study, they are set to be zero for simplicity. It is explained in the text that their value will not influence the final leakage inductance. Once the values of $\alpha_{n}^{1}$ and $\alpha_{n}^{4}$ are obtained, the relation equations (24) are applied to find all the parameters $\alpha_{0}^{i}, \beta_{0}^{i}, \alpha_{n}^{i}$ and $\beta_{n}^{i}$. More details related to this development are given in [46].

\section{REFERENCES}

[1] J. Aime, B. Cogitore, G. Meunier, E. Clavel, Y. Marechal, "Numerical Methods for Eddy Currents Modeling of Planar Transformers," IEEE Trans. Mag., vol.47, no.5, pp.1014-1017, May 2011.

[2] Z. Ouyang, M. A. E. Andersen, "Overview of Planar Magnetic Technology Fundamental Properties," IEEE Trans. Power Electron., vol.29, no.9, pp.4888-4900, Sep 2014.

[3] B.W. Carsten, "The low leakage inductance of planar transformers; fact or myth?," in Proc. Sixteenth Annual IEEE Applied Power Electronics Conference and Exposition (APEC), 2001, vol.2, pp.1184-1188.
[4] M. Pahlevaninezhad, D. Hamza, P.K. Jain, ”An Improved Layout Strategy for Common-Mode EMI Suppression Applicable to High-Frequency Planar Transformers in High-Power DC/DC Converters Used for Electric Vehicles," Trans. Power Electron., vol.29, no.3, pp.1211-1228, May 2014.

[5] Colonel Wm. T. McLyman, Transformer and Inductor Design Handbook, 3rd ed. Boca Raton, FL: CRC Press, 2004.

[6] Z. Ouyang, O.C. Thomsen, M. Andersen, "Optimal Design and Tradeoff Analysis of Planar Transformer in High-Power DCDC Converters," IEEE Trans. Ind. Electron., vol.59, no.7, pp.2800-2810, Jul. 2012.

[7] H. de Groot, E. Janssen, R. Pagano, K. Schetters, ”Design of a 1-MHz LLC Resonant Converter Based on a DSP-Driven SOI Half-Bridge Power MOS Module," Trans. Power Electron., vol.22, no.6, pp.2307-2320, Novembre 2007.

[8] J-H. Jung; , "Bifilar Winding of a Center-Tapped Transformer Including Integrated Resonant Inductance for LLC Resonant Converters," IEEE Trans. Power Electron., vol.28, no.2, pp.615-620, Feb. 2013.

[9] K-B. Park, B-H. Lee, G-W Moon, M-J. Youn, "Analysis on CenterTap Rectifier Voltage Oscillation of LLC Resonant Converter," Power Electronics, IEEE Trans. Power Electron., vol.27, no.6, pp.2684-2689, June 2012.

[10] J. Ferrell, J.-S. Lai, T. Nergaard, X. Huang, L. Zhu, and R. Davis, "The role of parasitic inductance in high-power planar transformer design and converter integration," in Proc. IEEE APEC, 2004, pp. 510-515.

[11] Y. Wang, S. W. H. de Haan, J. A. Ferreira, "Design of low-profile nanocrystalline transformer in high-current phase-shifted DC-DC converter," Energy Conversion Congress and Exposition (ECCE), 2010 IEEE, pp.2177-2181, 12-16 Sept. 2010.

[12] M. Vuksic, S.M. Beros, L. Vuksic, "The Multiresonant Converter Steady-State Analysis Based on Dominant Resonant Process," IEEE Trans. Power Electron., vol.26, no.5, pp.1452-1468, May 2011.

[13] Z. Ouyang; O.C. Thomsen, M. Andersen, "Planar-Integrated Magnetics (PIM) Module in Hybrid Bidirectional DCDC Converter for Fuel Cell Application," IEEE Trans. Power Electron., vol.26, no.11, pp.3254-3264, Nov. 2011.

[14] S. Wang; C. Xu, "Design Theory and Implementation of a Planar EMI Filter Based on Annular Integrated InductorCapacitor Unit," IEEE Trans. Power Electron., vol.28, no.3, pp.1167-1176, March 2013.

[15] W. Tan, C. Cuellar , X. Margueron, N. Idir, "A Common-Mode Choke Using Toroid-EQ Mixed Structure," IEEE Trans. Power Electron., vol. 28, no.1, pp.31-35, Jan. 2013.

[16] X. Wu, D. Xu, Z. Wen, Y. Okuma, and K. Mino, "Design, modeling, and improvement of integrated EMI filter with flexiblemultilayer foils," IEEE Trans. Power Electron., vol. 26, no. 5, pp. 1344-1354, May 2011.

[17] R. Lai, Y. Maillet, F. Wang, S. Wang, R. Burgos, and D. Boroyevich,

$$
\begin{gathered}
\left\{\begin{array}{l}
\alpha_{0}^{i} H_{i}+\beta_{0}^{i}+\sum_{n=1}^{\infty}\left[\alpha_{n}^{i} \operatorname{ch}\left(k_{n} H_{i}\right)+\beta_{n}^{i} \operatorname{sh}\left(k_{n} H_{i}\right)\right] \cos \left(k_{n} x\right)=\beta_{0}^{i+1}+\sum_{n=1}^{\infty} \alpha_{n}^{i+1} \cos \left(k_{n} x\right) \\
\frac{\alpha_{0}^{i}}{\mu_{i}}+\frac{1}{\mu_{i}} \sum_{n=1}^{\infty}\left[\alpha_{n}^{i} k_{n} \operatorname{sh}\left(k_{n} H_{i}\right)+\beta_{n}^{i} k_{n} \operatorname{ch}\left(k_{n} H_{i}\right)\right] \cos \left(k_{n} x\right)=\frac{1}{\mu_{i}}\left[\alpha_{0}^{i+1}+\sum_{n=1}^{\infty} \beta_{n}^{i+1} k_{n} \cos \left(k_{n} x\right)\right]
\end{array}\right. \\
\left\{\begin{array}{l}
\alpha_{0}^{j} H_{i}+\beta_{0}^{j}+\sum_{n=1}^{\infty}\left[\alpha_{n}^{j} \operatorname{ch}\left(k_{n} H_{j}\right)+\beta_{n}^{j} \operatorname{sh}\left(k_{n} H_{j}\right)\right] \cos \left(k_{n} x\right)=\beta_{0}^{j+1}+\sum_{n=1}^{\infty} \alpha_{n}^{j+1} \cos \left(k_{n} x\right) \\
\frac{\alpha_{0}^{j}}{\mu_{j}}+\frac{1}{\mu_{j}} \sum_{n=1}^{\infty}\left[\alpha_{n}^{j} k_{n} \operatorname{sh}\left(k_{n} H_{j}\right)+\beta_{n}^{j} k_{n} \operatorname{ch}\left(k_{n} H_{j}\right)\right] \cos \left(k_{n} x\right)-\frac{\alpha_{0}^{j+1}}{\mu_{j}}+\frac{1}{\mu_{j}} \sum_{n=1}^{\infty} \beta_{n}^{j+1} k_{n} \cos \left(k_{n} x\right)=\delta\left(x-x_{s}\right)
\end{array}\right.
\end{gathered}
$$


"An integrated EMI choke for differential-mode and common-mode noise suppression," IEEE Trans. Power Electron., vol. 25, no. 3, pp. 539-544, Mar. 2010.

[18] F. Luo, D. Boroyevich, P. Mattevelli, K. Ngo, D. Gilham, and N. Gazel, "An integrated common mode and differential mode choke for EMI suppression using magnetic epoxy mixture," in Proc. IEEE Appl. Power Electron. Conf. Expo., 2011, pp. 1715-1720.

[19] R. Chen, J. V. Wyk, S. Wang et W. Odendaal, "Improving the Characteristics of integrated EMI filters by embedded conductive Layers," IEEE Trans. Power Electron., vol. 20, p. 611-619, May 2005.

[20] M. Pavlovsky, S. W. H. de Haan, J. A. Ferreira, "Winding Losses in High-Current, High-Frequency Transformer Foil Windings with Leakage Layer,' Power Electronics Specialists Conference, 2006. PESC '06. 37th IEEE, pp.1,7, 18-22 June 2006.

[21] R. Prieto, J. A. Cobos, O. Garcia, P. Alou, J. Uceda, "Taking into account all the parasitic effects in the design of magnetic components," Applied Power Electronics Conference and Exposition, 1998. APEC '98. Conference Proceedings 1998., Thirteenth Annual, vol.1, pp.400-406, 15 19 Feb 1998.

[22] R. Prieto, J. A. Cobos, O. Garcia, P. Alou, P.; J. Uceda, "Study of 3-D magnetic components by means of "double 2-D" methodology," IEEE Trans. Ind. Elec., vol.50, no.1, pp.183-192, Feb 2003.

[23] R. Doebbelin, M. Benecke, A. Lindemann, "Calculation of leakage inductance of core-type transformers for power electronic circuits," Power Electronics and Motion Control Conference, 2008. EPE-PEMC 2008. 13th , pp.1280-1286, 1-3 Sept. 2008.

[24] P. Dowell, "Effects of eddy currents in transformer windings," Proceedings of the Institution of Electrical Engineers, vol. 113, pp. 1387-1394, Aug. 1966.

[25] W. G. Hurley, W. H. Wolfle, Transformers and Inductors for Power Electronics: Theory, design and applications, Wiley, 2013, ISBN:978-1119-95057-8

[26] J. P. Ferrieux and F. Forest, Alimentations a Decoupage, Convertisseurs a Resonance, 2nd ed. Paris, France: Masson, 1994.

[27] R. Prieto, J. A. Oliver, J. A. Cobos, M. Christini, ”Magnetic Component Model for Planar Structures Based on Transmission Lines," IEEE Trans. Ind. Electron., vol. 57, no.5, p.1663-1669, May 2010.

[28] R. Pittini, Z. Zhe, Z. Ouyang, M. A. E. Andersen, O. C. Thomsen, "Analysis of planar E+I and ER+I transformers for low-voltage highcurrent DC/DC converters with focus on winding losses and leakage inductance," in Proc. 7th International Power Electronics and Motion Control Conference (IPEMC), 2012, vol.1, pp.488-493, 2-5 June 2012.

[29] J. Li; C. Hu; X. Pang, "Analysis of the leakage inductance of planar transformer," in Proc. 9th International Conference on Electronic Measurement \& Instruments (ICEMI) pp.1-273-1-276, 16-19 Aug. 2009.

[30] Z. Ouyang; O.C. Thomsen, M. Andersen, "The analysis and comparison of leakage inductance in different winding arrangements for planar transformer," in Proc. International Conference on Power Electronics and Drive Systems, pp.1143-1148, 2-5 Nov. 2009.

[31] R. Chen, W. S., J. van Wyk et W. Odendaal, "Integration of EMI filter for distributed power system (DPS) front-end converter," in Proceeding of IEEE 34th Annual Power Electronics Specialist Conference, 2003

[32] F. De Leon, S. Purushothaman, L. Qaseer, "Leakage Inductance Design of Toroidal Transformers by Sector Winding," IEEE Trans. Power Electron., vol.29, no.1, pp.473-480, Jan. 2014.

[33] A. Taher, S. Sudhoff, S. Pekarek, "Calculation of a Tape-Wound Transformer Leakage Inductance Using the MEC Model," IEEE Trans. Energy Conversion, vol.30, no.2, pp.541-549, June 2015.

[34] M. A. Bahmani, T. Thiringer, "Accurate Evaluation of Leakage Inductance in High-Frequency Transformers Using an Improved FrequencyDependent Expression," IEEE Trans. Power Electron., vol. 30, no.10, pp. 5738-5745, Oct. 2015

[35] Z. Ouyang, J. Zhang, W. G. Hurley, "Calculation of Leakage Inductance for High-Frequency Transformers," IEEE Trans. Power Electron., vol. 30, no. 10, pp. 5769-5775, Oct. 2015.

[36] P. Hammond, "Roth's method for the solution of boundary-value problems in electrical engineering", PROC. IEE, Vol. 114, No. 12, december 1967.

[37] J. Zhang, Z. Ouyang, M. Duffy, M. Andersen, G. Hurley, 'Leakage Inductance Calculation for Planar Transformers with a Magnetic Shunt," IEEE Trans. on Ind. Appl., vol. 50, no. 6, pp. 4107-4112, Nov./Dec. 2014.

[38] X. Margueron, J-P. Keradec and D. Magot, "Analytical Calculation of Static Leakage Inductances of H.F. Transformers Using PEEC Formulas," IEEE Trans. on Ind. Appl., vol. 43, No. 4, pp.884-892, July/August 2007.

[39] X. Margueron, A. Besri, P-O. Jeannin, J-P. Keradec and G. Parent, "Complete Analytical Calculation of Static Leakage Parameters: A step toward HF Transformer Optimization," IEEE Trans. on Ind. Appl., vol. 46, No. 3, pp.1055-1063, May/June 2010.

[40] J. D. Stratton, Electromagnetic Theory, New York: McGraw-Hill, 1941, ch. 4.

[41] W. A. Roshen, "Analysis of planar sandwich inductors by current images," IEEE Trans. Magn., vol. 26, no. 5, pp. 2880-2887, Sep. 1990.

[42] M. Lambert, F. Sirois, M. Martinez-Duro, J. Mahseredjian, "Analytical Calculation of Leakage Inductance for Low-Frequency Transformer Modeling," IEEE Trans. Power Delivery, vol.28, no.1, pp.507-515, Jan. 2013.

[43] K. J. Binns, P. J. Lawrenson, and C. W. Trowbridge, The Analytical and Numrical Solution of Electric and Magnetic Fields. Hoboken, NJ: Wiley.

[44] P. Olver, Introduction to Partial Differential Equations, Minnesota, USA, 2012.

[45] W. Tan, X. Margueron, N. Idir, "Analytical modeling of parasitic capacitances for a planar common mode inductor in EMI filters," in Power Electronics and Motion Control Conference (EPE/PEMC), 2012 15th International, pp.DS3f.2-1,DS3f.2-6, 4-6 Sept. 2012.

[46] W. Tan, Modeling and Design of Passive Planar Components for EMI Filters, Ecole Centrale de Lille, PhD Thesis, november 2012.

[47] L. Landau and E. Lifchitz, Electrodynamique des milieux continus. Moscou, Russia: Mir, 1969, pp. 186-187.

[48] User's Guide - Maxwell 2D Version 15, ANSYS Inc, March 2012.

[49] Ferroxcube, http://www.ferroxcube.com

[50] EPCOS, http://www.epcos.com

[51] R. Garg, Analytical and Computational Methods in Electromagnetics, London Artech House, 2008.

[52] Agilent 4294A Precision Impedance Analyser-Operation Manual, Agilent Technologies.

[53] X. Margueron, J-P. Keradec, "Identifying the Magnetic Part of the Equivalent Circuit of n-Winding Transformer," IEEE Trans. Instru. and Meas., vol.56, no.1, pp.146-152, Feb. 2007.

[54] R. Prieto, J. A. Cobos, O. Garcia, P. Alou, J. Uceda, "Using parallel windings in planar magnetic components," Power Electronics Specialists Conference, 2001. PESC. 2001 IEEE 32nd Annual, vol.4, pp.2055-2060, 2001.

[55] X. Margueron, A. Besri, Y. Lembeye, J-P. Keradec, "Current Sharing Between Parallel Turns of a Planar Transformer: Prediction and Improvement Using a Circuit Simulation Software," IEEE Trans. on Ind. Appl., vol. 46, No. 3, pp.1064-1071, May/June 2010.

[56] M. Pavlovsky, S. W. H. de Haan, J. A. Ferreira, "Partial Interleaving: A Method to Reduce High Frequency Losses and to Tune the Leakage Inductance in High Current, High Frequency Transformer Foil Windings," Power Electronics Specialists Conference, 2005. PESC '05. IEEE 36th, pp.1540-1547, 16-18 June 2005.

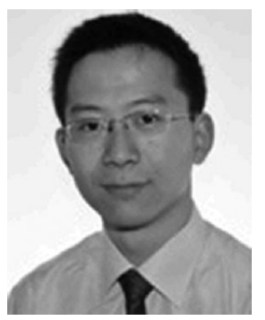

Wenhua Tan was born in Jiangsu, China, in 1984. He received B.E. and M.E. degrees from the Xian Jiaotong University, Xian, China, in 2006 and 2009, respectively, and the Eng. degree from the Ecole Centrale de Lyon, Ecully, France, in 2009. From 2009 to 2012, he had been working toward the Ph.D. degree in electrical engineering in the Ecole Centrale de Lille, Universite Lille Nord de France, Villeneuve d'Ascq, France.

His main research interests include passive comand EMI filters design ponent integration, passive component modeling, 


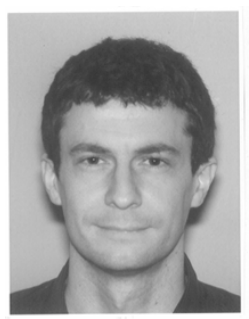

Xavier Margueron (M'09) was born in Chambery, France, in 1980. He received the diploma of Electrical Engineering from the Ecole Nationale Superieure d'Ingenieurs Electriciens de Grenoble, Saint Martin d'Heres, France, in 2003 and the PhD Degree in Electrical Engineering from the Universite Joseph Fourier, Grenoble, France, in 2006. Its principal fields of research related to passive components and HF modelling.

Since September 2007, he has been an associate professor at the Ecole Centrale de Lille, France, where he carries out research in the L2EP laboratory. His research interests include modeling and optimization of HF magnetic passive components for power electronic converters and planar magnetic technology.

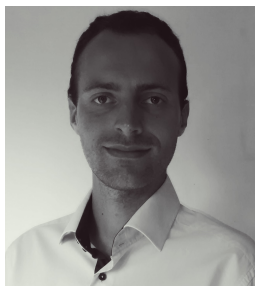

Laurent Taylor was born in Dunkerque, France, in 1987. He received the M.S. degree from Ecole Normale Superieure de Cachan, France in 2011, and from Ecole Centrale de Lille, France in 2012. He's currently working toward Ph.D. degree in Power Electronics and Modeling at the Laboratoire d'Electrotechnique et d'Electronique de Puissance, Lille, France.

His research interests include HF power electronics, passive component modeling and model order reduction methods.

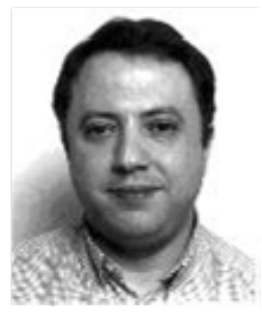

Nadir Idir (M'93) received the Ph.D. degree in electrical engineering from the University of Lille 1, Villeneuve-dAscq, France, in 1993.

He is currently a Full Professor with IUT A of the University of Lille 1, where he teaches power electronics and electromagnetic compatibility. Since 1993, he has been with the Laboratory of Electrical Engineering and Power Electronics, University of Lille 1. His research interests include design methodologies for HF switching converters, power devices ( $\mathrm{SiC}$ and $\mathrm{GaN}$ ), electromagnetic compatibility of the static converters, HF modeling of the passive components, and EMI filter design methodologies. 